\title{
Joint NMR and Diffraction Studies of Catalyst Structure and Binding
}

\section{(I) ${ }^{17} \mathrm{O}$ and ${ }^{1} \mathrm{H}$ NMR Studies of Acidity}

Brønsted acid sites play a key role in controlling the catalytic performances of acidic catalysts. A determination of the structure of the acid site, in particular, the O-H bond length, is important for the understanding of acid strength. We have been using a series of double resonance NMR methods that have been designed to measure O-H distances, which are based on the dipolar coupling between the ${ }^{1} \mathrm{H}$ and ${ }^{17} \mathrm{O}$ nuclei. The dipolar coupling is proportional to $1 / \mathrm{r}^{3}$, where $\mathrm{r}$ is the $\mathrm{O}-\mathrm{H}$ internuclear distance. The $1^{\text {st }}$ challenge is to enrich the zeolitic materials in ${ }^{17} \mathrm{O}$ at a sufficiently high level to allow these experiments to be performed. T. Unfortunately, for the methods to work, the O-H bonds must be rigid on the timescale of the $\mathrm{O}-\mathrm{H}$ dipolar coupling $(\mathrm{kHz})$ and the apparent $\mathrm{O}-\mathrm{H}$ distances in zeolite $\mathrm{HY}$ and HZSM-5 extracted from ${ }^{17} \mathrm{O}-{ }^{1} \mathrm{H}$ double resonance NMR acquired at room temperature are noticeably longer than those extracted from $a b$-initio calculations. This was ascribed to the presence of some restricted motions at room temperature, such as zeolite framework vibrations and O-H librational motion. Thus, one aim of the $1^{\text {st }}$ study completed during this work period was to investigate the protonic motion in zeolite HZSM- 5 by low temperature ${ }^{1} \mathrm{H}$ MAS NMR behavior spectroscopy, and important goal being to reconcile differences between different studies in the literature. To this end, we investigated samples that have been dried using procedures that are standard in the literature, and samples that have been more carefully dehydrated. A significant enhancement of proton mobility is seen for the "standard" dehydrated HZSM-5 sample, in comparison to that seen for the much drier sample. The increase in motion is ascribed to a vehicle-hopping mechanism involving the residual water that is present in these zeolites. A gradual change of the framework structure is observed on cooling to approx. $213 \mathrm{~K}$, as monitored via the change in ${ }^{1} \mathrm{H}$ chemical shift values of the Brønsted acid resonances and by X-ray diffraction. A more sudden change in structure is seen 
by differential scanning calorimetry (DSC) and NMR, at approx. 220 - $230 \mathrm{~K}$, which is associated with changes in both the mobility and the modes of binding of the residual water to the Brønsted acid sites and the zeolite framework.

Following our investigation of the protonic mobility in these systems, we have used the double resonance method REDOR spectroscopy to measure the O-H distances in zeolites HY and HZSM-5 at low temperatures (183K), where many of the motions are frozen out. By comparing the line shapes obtained by simulation with the experimental data, an $\mathrm{O}-\mathrm{H}$ distance of $\sim 0.97$ $0.98 \AA$ was obtained for zeolite $\mathrm{HY}$, which is consistent with the previous ab-initio calculation results. The results demonstrate that low temperature REDOR NMR can provide more accurate estimates of the $\mathrm{O}-\mathrm{H}$ distance, which should prove useful in structure-function correlations and as a method to explore the effects of hydrogen-bonding.

\section{(II) Nitrided Zeolites}

Our second major activity has focused on increasing basicity in zeolites. In a collaboration with Profs. Scott Auerbach and Kurt Conner at U. Massachusetts, Amherst, we have investigated the effect of nitriding zeolites with flowing ammonia on the structure and properties of zeolitic materials. Nitrogen substituted zeolites with high crystallinity and microporosity are obtained by nitrogen (strictly, -NH) substitution for oxygen in zeolite Y. The substitution reaction is performed under ammonia flow by varying the temperature and reaction time. We have examined the effect of aluminum content and charge-compensating cation $\left(\mathrm{H}^{+}\right.$vs. $\mathrm{Na}^{+}$) on the degree of nitrogen substitution and on the preference for substitution of $\mathrm{Si}-\mathrm{O}-\mathrm{Al}$ vs. Si-O-Si linkages in the FAU zeolite structure. Silicon-29 Magic Angle Spinning (MAS)

Nuclear Magnetic Resonance (NMR) and ${ }^{1} \mathrm{H} /{ }^{29}$ Si Cross Polarization MAS NMR spectroscopy have been used to probe the different local environments of the nitrogen-substituted zeolites. Experimental data are compared to simulated NMR spectra obtained by constructing a 
compendium (>100) of zeolite clusters with and without nitrogen, and by performing quantum calculations of chemical shifts for the NMR-active nuclei in each cluster. The simulated NMR spectra, which assume peak intensities predicted by statistical analysis, agree remarkably well with the experimental data. The results show that high levels of nitrogen substitution can be achieved while maintaining porosity, particularly for $\mathrm{NaY}$ and low-aluminum $\mathrm{HY}$ materials, without significant loss in crystallinity. Experiments performed at lower temperatures (750$800^{\circ} \mathrm{C}$ ) show a preference for substitution at $\mathrm{Si}-\mathrm{OH}-\mathrm{Al}$ sites. No preference is seen for reactions performed at higher temperatures and longer reaction times (e.g., $850{ }^{\circ} \mathrm{C}$ and 48 hours).

\section{Published Papers with DOE BES Support (2006-March 2011)}

1. "An atomistic MD simulation and pair-distribution-function study of disorder and reactivity of $\alpha-\mathrm{AlF}_{3}$ nanoparticles”, S. Chaudhuri, P.J. Chupas, B.J. Morgan, P.A. Madden and C.P. Grey, Phys. Chem. Chem. Phys., 8, 5045-5055, (2006).

2. "17 O Magic Angle Spinning NMR Studies of Brønsted Acid Sites in Zeolites HY and HZSM-5, L. Peng, H. Huo, Y. Liu, and C. P. Grey, J. Am. Chem. Soc., 129, 335-346 (2007).

3. "Probing bronsted acid sites in zeolite HY with low temperature O-17 MAS NMR spectroscopy”, H. Huo, L.M. Peng, C.P. Grey, 15th Inter. Zeolite Conf., Beijing, China, (12-17 Aug 2007). Editors: R. Xu, Z. Gao, J. Chen, W. Yan,. From zeolites to porous MOF materials: The $40^{\text {th }}$ Anniversary of Inter. Zeolite Conf. Proc. of the $15^{\text {th }}$ Inter. Zeolite Conf., Elsevier, 170: 783-789, (2007).

4. "Probing Brønsted acid sites in zeolite HY with low temperature ${ }^{17}$ O MAS NMR spectroscopy”, Stud. Surface Sci. Catal., 170, 783-789 (2007).

5. "Watching Nanoparticles Grow: The Mechanism and Kinetics for the Formation of $\mathrm{TiO}_{2}$-Supported Platinum Nanoparticles", P. J. Chupas, K. W. Chapman, G. Jennings, P. L. Lee and Clare P. Grey, J. Am. Chem. Soc., 129, 13822-13824, (2007). Highlighted as an "Editors' Choice" in Science, Nov. 9, p.889, (2007).

6. " ${ }^{17}$ O MQMAS NMR studies of zeolite HY”, L. Peng, H. Huo, Z. Gan and C. P. Grey, Microporous Mesoporous Mater., 109, 156-162, (2008).

7. "Diphosphine probe molecules and solid-state NMR investigations of proximity between acidic sites in zeolite HY", L.M. Peng and C.P. Grey, Micropor. Mesopor. Mat., 116, 277-283, (2008).

8. "A versatile sample-environment cell for non-ambient X-ray scattering experiments", P.J. Chupas, K.W. Chapman, C. Kurtz, J.C. Hanson, P.L. Lee and C.P. Grey, J. Applied. Crystallogr., 41, 822-824, (2008).

9. "Variable temperature ${ }^{17} \mathrm{O}$ NMR study of oxygen motion in the anionic conductor $\mathrm{Bi}_{26} \mathrm{Mo}_{10} \mathrm{O}_{69}$, L. Holmes, L.M. Peng, I. Heinmaa, L.A. O’Dell, M.E. Smith, R.-N. Vannier and C.P. Grey, Chem. Mater., 20, 3638-3648, (2008). 
10. “Spectroscopic signatures of nitrogen-substituted zeolites”, K.D. Hammond, F. Dogan, G.A. Tompsett, V. Agarwal, W.C. Conner, C.P. Grey and S.M. Auerbach, J. Am. Chem. Soc., 130, 14912-14913, (2008).

11. "Low temperature ${ }^{1} \mathrm{H}$ MAS NMR spectroscopy studies of proton motion in zeolite HZSM-5”, H. Huo, L.M. Peng and C.P. Grey, J. Phys. Chem. C, 113, 8211-8219, (2009).

12. "Application of high-energy X-rays and pair-distribution-function analysis to nano-scale structural studies in catalysis”, P.J. Chupas, K.W. Chapman, H.L. Chen and C.P. Grey, Catalysis Today, 145, 213-219, (2009).

13. "Searching for microporous, strongly basic catalysts: Experimental and calculated ${ }^{29} \mathrm{Si}$ NMR spectra of heavily nitrogen-doped Y zeolites”, F. Dogan, K.D. Hammond, G.A. Tompsett, H. Huo, W.C. Conner, Jr., S.M. Auerbach and C.P. Grey, J. Am. Chem. Soc., 131, 11062-11079, (2009).

14. "Optimizing the synthesis of nitrogen-substituted zeolites”, K.D. Hammond, M. Gharibeh, G.A. Tompsett, F. Dogan, A.V. Brown, C.P. Grey, S.M. Auerbach and W.C. Conner, Jr., Chem. Mater., 22, 130-142, (2010).

15. "Measuring Brønsted acid site $\mathrm{O}-\mathrm{H}$ distances in zeolites HY and HZSM-5 with lowtemperature ${ }^{17} \mathrm{O}-{ }^{1} \mathrm{H}$ double resonance MAS NMR spectroscopy”, H. Huo, L.M. Peng and C.P. Grey, J. Phys. Chem. C, 115, 2030-2037, (2011).

16. "Liquid phase aldol condensation reactions with $\mathrm{MgO}-\mathrm{ZrO}_{2}$ and shape-selective nitrogensubstituted NaY”, W.Q. Shen, G.A. Tompsett, K.D. Hammond, R. Xing, F. Dogan, C.P. Grey, W.C. Conner, S.M. Auerbach and G.W. Huber, Appl. Catal. A-Gen., 392, 57-68, (2011). 